\title{
Assessment of airborne microbial community in Indian cities during the Middle East dust storm
}

\author{
Vikas C. Ghattargi, Mani Garg, Sudeeksha Raina, Jovita D. Silva, \\ Shrikant P. Pawar, Praveen Rahi and Yogesh S. Shouche* \\ National Centre for Microbial Resource, National Centre for Cell Science, Pune 411 007, India
}

Globally dust storms have greatly affected air quality, and nearly 5.0 billion tonnes of dust undergoes migration every year. A plethora of microorganisms spread far and wide along with the dust particles during dust storms. In April 2015, a dust storm originated from the Middle East and travelled to many Indian cities. We analysed the impact of the dust storm on the diversity and composition of aerial microorganisms using cultivation-based methods. Sampling was done in three cities (Mumbai, Lonavala and Pune) during a dust storm day (DSD) and a post-dust storm day (PSD). A total of 580 morphologically different bacteria and then ten mycelial fungi were isolated during the study. Identification based on MALDI-TOF MS biotyping, sequencing of $16 \mathrm{~S}$ rRNA gene and ITS region revealed that the bacterial isolates belonged to 32 different genera and fungi to four different genera. Principal coordinate analysis exhibited separate grouping of DSD and PSD samples, indicating the shift in microbial communities. Osmotolerant and halotolerant bacterial genera, viz. Psychrobacter and Exiguobacterium were recorded specifically during DSD. The proportion of opportunistic pathogens, including Staphylococcus and Enterobacter was high during DSD in comparison to PSD. Overall, the study reveals the influence of dust storms on the aerial microbial composition and indicates the possible spread of specific microbial species during a dust storm event.

Keywords: Airborne, dust storm, high-throughput cultivation, microorganisms, mass spectroscopy.

THE study on migration and spread of microorganisms has lured researchers since long, because of its likely impacts on the environment, human and animal health ${ }^{1}$. The primary modes of microbial dispersion involve currents of water and wind and can survive through harsh conditions efficiently, thus establishing their presence and growth in new lands ${ }^{2}$. Dust storms originate when high-velocity winds blow-off the topsoil from the dry

\footnotetext{
*For correspondence. (e-mail: yogesh@nccs.res.in)
}

grounds and deserts ${ }^{3}$. These strong wind currents are known to blow-off the topsoil particles, dust and soilinhabiting microbes being carried by the wind. A minimum of 1 million tonnes of airborne soil is known to circumvent the earth in a year, carrying approximately $10^{16}$ dust-borne bacteria ${ }^{4}$. Microbiological analyses of dust storm aerosol samples have proven the presence of marine bacteria, plant pathogens and animal pathogens which cause outbreaks of infection and disease ${ }^{5}$.

Dust Storms are frequent in the Sahara desert located in the Northern Africa, Taklamakan and Badain Jaran deserts of China, and the Arabian desert stretching from Yemen and Oman to Jordan and Iraq ${ }^{6}$. Phenomena such as suspension and saltation are responsible for the drifting of fine dust particles and microbes over extremely long distances $^{7}$. These processes affect coral reefs, impact human health, fertilize oceans, influence photochemistry and cloud formation and also carry microorganisms ${ }^{8}$. Previously, African dust storms have transported pathogenic Aspergillus species that caused aspergillosis in the sea fans of Virgin Islands ${ }^{8}$. Air samples over the Arctic and Atlantic waters were found to carry microorganisms that were similar to the microorganisms recovered from the Caribbean atmosphere 9 . These studies indicate that dust storms are a major factor in the transport of microbes, helpful or harmful, making it important to characterize the microbial diversity of a dust storm to ensure its impact on environmental health.

On 2 April 2015, an intense dust storm was seen spanning over the Middle East and by 4 April, it was visibly moving towards the Indian peninsula. The storm hit the Arabian coast on 7 April 2015, affecting parts of Maharashtra and significantly reduced visibility of the affected areas. This was further confirmed by satellite images (Figure $1 i$ ). The present study was undertaken to enhance our understanding of the status of dust-borne microorganisms reaching the Indian peninsula travelling from the Gulf countries and also to determine if culturable populations could be detected after travelling more than $2000 \mathrm{~km}$ across the Arabian Sea. Moreover, we also evaluated airborne microbial community on a dust storm day (DSD) and on a post-dust storm day (PSD) in three Indian cities. 


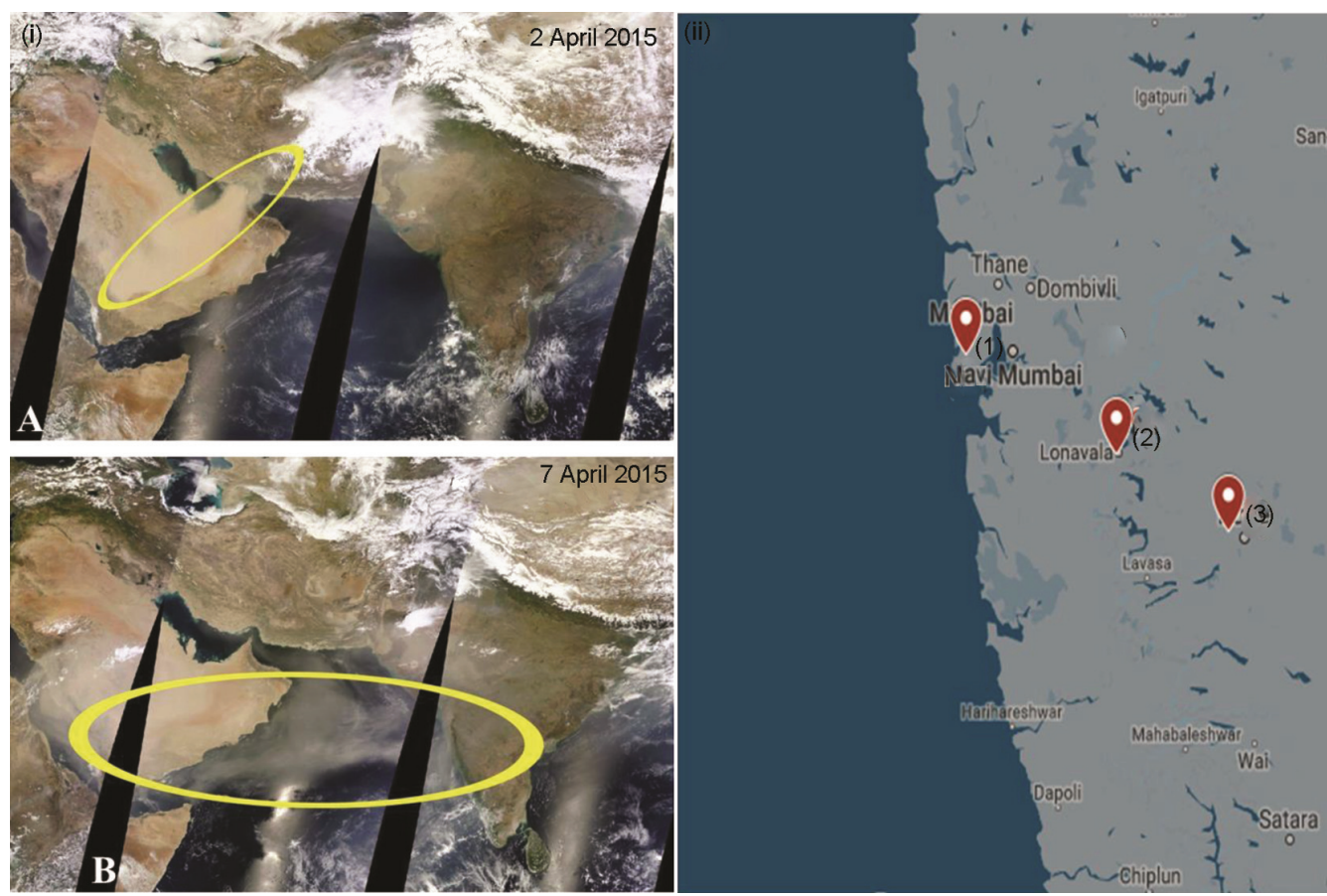

Figure 1. Satellite images of the dust storm, (A) its origin at the Arabian Peninsula on 2 April 2015 and (B) reaching the Indian peninsula on 7 April 2015, Source: earthdata.nasa.gov. Sample collection sites marked in the state of Maharashtra, India, (site 1) Mumbai $\left(19.07^{\circ} \mathrm{N}, 72.87^{\circ} \mathrm{E}\right.$, elevation $14 \mathrm{~m}$ amsl); (site 2) Lonavala $\left(18.75^{\circ} \mathrm{N}, 73.4^{\circ} \mathrm{E}, e^{\circ}\right.$ elevation $624 \mathrm{~m}$ amsl); and (site 3$)$ Pune $\left(18.5^{\circ} \mathrm{N}, 73.85^{\circ} \mathrm{E}\right.$, elevation $562 \mathrm{~m}$ amsl).

\section{Materials and methods}

\section{Sample sites}

With the dust storm moving towards the Indian peninsula from the Arabian coast, samples were collected at three sites in Maharashtra, India. All locations were chosen with varying distances from the coast-Mumbai $\left(19.07^{\circ} \mathrm{N}\right.$, $72.87^{\circ} \mathrm{E}$, elevation $14 \mathrm{~m}$ amsl which is along the coast of Maharashtra, Lonavala $\left(18.75^{\circ} \mathrm{N}, 73.4^{\circ} \mathrm{E}\right.$, elevation $624 \mathrm{~m}$ amsl) at a distance of $95 \mathrm{~km}$ from the coast and Pune city $\left(18.5^{\circ} \mathrm{N}, 73.85^{\circ} \mathrm{E}\right.$, elevation $\left.562 \mathrm{~m} \mathrm{amsl}\right)$ around $203 \mathrm{~km}$ away from the seashore (Figure 1 ii). Mumbai city is situated along the coast while Lonavala is located on Sahyadri mountain slopes and Pune on the Deccan Plateau.

\section{Humidity, velocity and particulate matter}

Data on humidity, velocity and particulate matter $\left(\mathrm{PM}_{2.5}\right.$ and $\mathrm{PM}_{10}$ ) were shared by the Indian Institute of Tropical Meteorology (IITM) Pune, which were collected under the System of Air Quality and Weather Forecasting and Research (SAFAR) project.

\section{Collection of samples}

Sampling was performed by exposing pre-sterilized culture plates of different media to air at the three locations. Two batches of sterile culture media plates were exposed for 20 and $60 \mathrm{~min}$ respectively. The media used were Reasoner's 2A agar, nutrient agar, dilute nutrient agar $(1: 10)$, actinomycete isolation agar, rose bengal agar and water agar. The plates were incubated at $27^{\circ} \mathrm{C}$ for 24,48 and $72 \mathrm{~h}$. A pure culture of each isolate was stored in $20 \%$ glycerol as frozen stock at $-80^{\circ} \mathrm{C}$.

\section{Identification using mass spectrometry}

Different morphotypes were chosen from each plate and pure bacterial cultures were subjected to Matrix-Assisted Laser Desorption/Ionization Time of Flight Mass Spectrometry (MALDI TOF-MS). A thin film of bacterial cells was coated with $1 \mu l$ of $\alpha$-cyano-4-hydroxycinnamic acid (HCCA) $(10 \mathrm{mg} / \mathrm{ml})$ matrix, dried and subjected to further analysis. Ethanol/formic acid extraction method was used for the samples that could not generate MALDITOF mass spectra by direct sample method ${ }^{10}$. Principal component analysis (PCA) dendrograms were generated using MALDI Biotyper software for isolates from each sampling location.

\section{$16 S$ rRNA gene sequencing}

DNA isolation was done with the Invitrogen PureLink Pro96-Genomic DNA isolation kit using the manufacturer's protocol. The DNA was quantified by NanoDrop ${ }^{\mathrm{TM}}$. The $16 \mathrm{~S}$ region of the genomic DNA was then amplified using $16 \mathrm{~S}$ specific amplification primers $27 \mathrm{~F}$ and $1525 \mathrm{R}$ 
Table 1. Concentration of particulate matter during dust storm and normal days

\begin{tabular}{|c|c|c|c|c|c|c|c|c|}
\hline \multirow[b]{2}{*}{ Location } & \multicolumn{4}{|c|}{ Dust storm day } & \multicolumn{4}{|c|}{ Normal day } \\
\hline & $\begin{array}{l}\text { PM } 2.5 \\
\left(\mu \mathrm{g} / \mathrm{m}^{3}\right)\end{array}$ & $\begin{array}{l}\text { PM } 10 \\
\left(\mu \mathrm{g} / \mathrm{m}^{3}\right)\end{array}$ & $\begin{array}{c}\text { Relative } \\
\text { humidity (\%) }\end{array}$ & $\begin{array}{l}\text { Velocity } \\
(\mathrm{km} / \mathrm{h})\end{array}$ & $\begin{array}{l}\text { PM } 2.5 \\
\left(\mu \mathrm{g} / \mathrm{m}^{3}\right)\end{array}$ & $\begin{array}{l}\text { PM } 10 \\
\left(\mu \mathrm{g} / \mathrm{m}^{3}\right)\end{array}$ & $\begin{array}{c}\text { Relative } \\
\text { humidity (\%) }\end{array}$ & $\begin{array}{l}\text { Velocity } \\
(\mathrm{km} / \mathrm{H})\end{array}$ \\
\hline Mumbai & 170.6 & 102.5 & 67 & 34 & 68.07 & 153.6 & 60 & 8.5 \\
\hline Lonavala & 111.7 & 80.12 & 44 & 32 & 50.12 & 130.1 & 40 & 9 \\
\hline Pune & 52.88 & 57.9 & 20 & 32 & 31.78 & 98.28 & 22 & 9.3 \\
\hline
\end{tabular}

*Data collected by System of Air Quality and Weather Forecasting and Research (SAFAR) systems, IITM, Pune.

Table 2. Colony forming units on the respective media at different exposure times

\begin{tabular}{lcccccc}
\hline Location & Exposure time (min) & R2A & NA & DNA & AIA & WA \\
\hline Pune & DS20 & $201^{\mathrm{d}}$ & $44^{\mathrm{bc}}$ & $74^{\mathrm{b}}$ & $13^{\mathrm{bcd}}$ & $10^{\mathrm{abc}}$ \\
& DS60 & $280^{\mathrm{bc}}$ & $70^{\mathrm{ab}}$ & $85^{\mathrm{ab}}$ & $12^{\mathrm{bcd}}$ & $9^{\mathrm{abc}}$ \\
& CN20 & $103^{\mathrm{e}}$ & $35^{\mathrm{c}}$ & $25^{\mathrm{cd}}$ & $8^{\mathrm{cde}}$ & $7^{\mathrm{c}}$ \\
LN60 & $111^{\mathrm{e}}$ & $55^{\mathrm{abc}}$ & $32^{\mathrm{cd}}$ & $8^{\mathrm{cde}}$ & $11^{\mathrm{abc}}$ \\
& DS20 & $256^{\mathrm{c}}$ & $77^{\mathrm{ab}}$ & $96^{\mathrm{a}}$ & $15^{\mathrm{bc}}$ & $8^{\mathrm{bc}}$ \\
& DS60 & $280^{\mathrm{bc}}$ & $60^{\mathrm{abc}}$ & $88^{\mathrm{ab}}$ & $16^{\mathrm{b}}$ & $8^{\mathrm{bc}}$ \\
& CN20 & $85^{\mathrm{ef}}$ & $52^{\mathrm{abc}}$ & $26^{\mathrm{cd}}$ & $4^{\mathrm{e}}$ & $4^{\mathrm{c}}$ \\
& CN60 & $97^{\mathrm{ef}}$ & $40^{\mathrm{c}}$ & $22^{\mathrm{d}}$ & $5^{\mathrm{e}}$ & $16^{\mathrm{a}}$ \\
& DS20 & $300^{\mathrm{ab}}$ & $78^{\mathrm{ab}}$ & $44^{\mathrm{c}}$ & $39^{\mathrm{a}}$ & $15^{\mathrm{ab}}$ \\
& DS60 & $327^{\mathrm{a}}$ & $83^{\mathrm{a}}$ & $69^{\mathrm{b}}$ & $46^{\mathrm{a}}$ & $17^{\mathrm{a}}$ \\
& CN20 & $70^{\mathrm{f}}$ & $42 \mathrm{~b}^{\mathrm{c}}$ & $20^{\mathrm{d}}$ & $2^{\mathrm{e}}$ & $5^{\mathrm{c}}$ \\
& CN60 & $97^{\mathrm{ef}}$ & $40^{\mathrm{c}}$ & $40^{\mathrm{cd}}$ & $3^{\mathrm{e}}$ & $16^{\mathrm{a}}$ \\
\hline
\end{tabular}

Values are the mean of three replicates. Values with common letters in a column do not differ statistically according to Tukey's HSD test at $P \leq 0.01$. Here $\mathrm{a}>\mathrm{b}>\mathrm{c}>\mathrm{d}>\mathrm{e}>\mathrm{f}$. R2A, Reasoner's 2 agar; NA, Nutrient agar, DNA, Diluted nutrient agar; AIA, Actinomycete isolation agar; WA, Normal water agar.

(ref. 11). The amplified PCR product was purified by polyethylene glycol (Peg)- $\mathrm{NaCl}$ precipitation ${ }^{12}$. The DNA was then sequenced using a Sanger sequencer. The generated sequence was further edited using ChromasPro software and searched for identity in the $16 \mathrm{~S}$ rRNA gene sequence database and taxonomy search tool of EzBiocloud ${ }^{13}$. Newly generated sequences were submitted to NCBI Genbank and the accession numbers are listed in Supplementary Table 1.

\section{Statistical analysis}

Data on total microbial count were checked for normality and subjected to one-way analysis of variance (ANOVA) using the STATISTICA data analysis software system version 7 (StatSoft Inc., Tulsa, USA, 2004). We applied Good's coverage for a better understanding of the isolations performed ${ }^{14}$. We also applied Welch's $t$-test with Benjamini-Hochberg FDR correction to examine the significantly different bacterial families between normal and dust storm. Kruskal-Wallis test was applied to examine the location specific microbial species.

\section{Results}

\section{Particulate matter analysis}

The aerial particulate matter $\mathrm{PM}_{2.5}$ during the DSD (7 April 2015) ranged from 58.88 to 170.56 and showed significant $(P<0.05)$ increase in concentration in comparison to PSD (18 May 2015) from 31.78 to 68.07 (Table 1). In contrast, $\mathrm{PM}_{10}$ was more on PSD (range 98.28-153.62) in comparison to DSD (range 57.9-102.53). The aerial particulate matter and humidity were higher in Mumbai during both sampling days in comparison to Pune and Lonavala.

\section{Total microbial count}

The microbial count recorded on plates exposed during DSD was significantly high compared to that recorded during PSD (Table 2). Among different growth media, the highest microbial count was observed on R2A medium. The count on R2A plates during DSD was almost double in comparison to colony count on the same medium plates during PSD. Microbial colonies obtained on nutrient agar, dilute nutrient agar and actinomycete isolation agar showed significantly higher number in comparison to water agar and rose Bengal medium. An increase was observed in the number of colonies in plates with $60 \mathrm{~min}$ exposure in comparison to those exposed for $20 \mathrm{~min}$; however, this increase was not statistically significant.

\section{Identification of microorganisms}

A total of 283 isolates were selected from DSD samples based on their diverse morphotypes, while 286 isolates 


\section{RESEARCH ARTICLES}

were selected in case of PSD samples. MALDI-TOF MSbased identification resulted in $310(53.44 \%)$ isolates. In addition, good quality spectra were generated for 270 isolates. The PCA dendrograms constructed based on MALDI-TOF mass spectra of microbial isolates (163 and 152 isolates for PSD and DSD respectively) led to the grouping of isolates under 13 and 15 major clusters at similarity levels 6 and 5 for PSD and DSD samples respectively.

Next, 16S rRNA gene sequencing was carried out for 50 bacterial isolates including 37 isolates with no reliable identity found during comparison with the Biotyper database and 13 isolates randomly selected among the identified isolates by Biotyper. These 50 isolates belonged to various genera, viz. Bacillus, Micromonospora, Nocardiopsis, Lysinibacillus, Jeotgalicoccus, Curtobacterium, Arthrobacter, Exiguobacterium, Noviherbaspirillum, Gracilibacillus, Micromonospora, Streptomyces, Staphylococcus, Paracoccus, Psychrobacter, Ruegeria, Microbacterium, Brachybacterium, Stenotrophomonas, Providencia, Enterobacteria and Curvibacter (Supplementary Table 1). The identification results by MALDI-TOF MS and sequencing were comparable as there was no misidentification using both methods. The results of ITS gene sequencing of ten fungal isolates showed the presence of four genera, viz. Aspergillus, Alternaria, Curvularia and Cladosporium (Supplementary Table 2).

Table 3. Biodiversity indices calculated for normal and dust strom days

\begin{tabular}{lcc}
\hline Biodiversity index & Normal day & Dust strom day \\
\hline Number of genera & 17 & 21 \\
Shannon index & 4.88 & 5.07 \\
Simpson's index & 0.05 & 0.08 \\
Chao I & 36.39 & 36.61 \\
ACE & 39.39 & 41.12 \\
Jackknife & 40.89 & 41.81 \\
Good's coverage & 0.929 & 0.966 \\
\hline
\end{tabular}

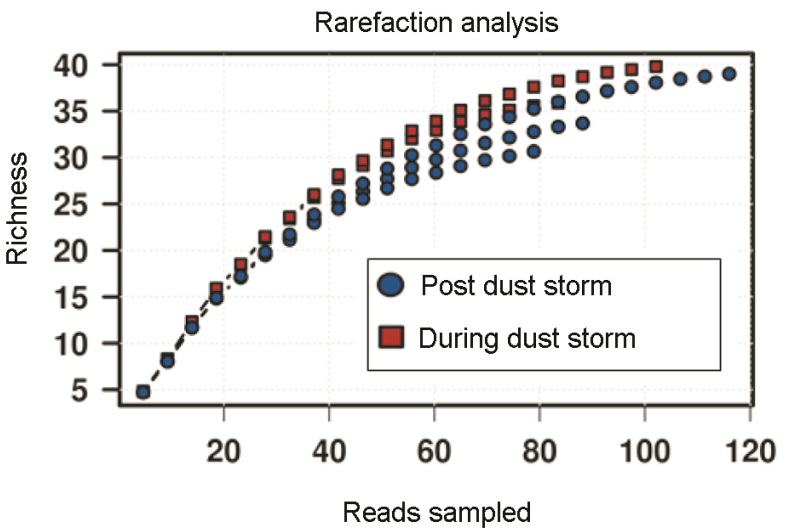

Figure 2. Rarefaction curves generated based on data number and identity isolates from post-dust storm day (PSD) and dust storm day (DSD) samples and analyses performed in CALYPSO using the furthest neighbour assignment algorithm.

\section{Biodiversity analyses}

Good's coverage indicated that a sufficient number of colonies was picked to represent bacterial diversity recovered in the growth media for both PSD and DSD samples (Table 3). Alpha diversity indices for Shannon, Simpson, Chao1, ACE and Jackknife were almost similar for both PSD and DSD. The rarefaction curve generated based on the presence, absence and abundance of unique microbial species recorded from each sample indicated that all the samples grew rapidly at first and then reached a plateau (Figure 2).

\section{Bacterial community composition}

The overall analysis of DSD and PSD samples revealed the presence of 92 different microbial species phylogenetically distributed across 32 genera which belong to four phyla, viz. Actinobacteria, Firmicutes, Proteobacteria and Bacteroides (Figure $3 a$ and $b$ ). Members of Bacillus, Arthrobacter, Staphylococcus, Kocuria, Streptomyces and Lysinibacillus were the most dominant during both PSD and DSD, representing 51\% of the total observed microbial species. The Venn diagram showed that members of the most dominating genera were present during both days, while 11 genera were uniquely present during PSD and 15 genera during DSD (Figure $4 a$ and b). Species-level comparisons exhibited a complete shift in microbial composition during both days at all sites (Supplementary Figure 1).

In the UniFracPCoA plot, all samples collected during PSD were placed on the negative side of PCoA1 while samples collected during DSD were placed separately on the positive side of PCoA1 (Figure 5). The mean abundance of bacterial genera was significantly different for PSD and DSD samples at $P<0.01$ (Figure 6). The differential genera during PSD were Arthrobacter, Masilla, Noviherbaspirillum and Ochrobactrium, and during DSD Arthrobacter, Brachybacterium, Curtobactrium, Curvibacter, Dietiza, Enterobacter, Ensifer, Exigobactrium, Jeotgalicoccus, Providencia, Regureia and Serratia.

\section{Discussion}

Dust deposition during dust storms has been considered relevant for nutrient deposition and soil development ${ }^{15-17}$. Recent studies on the shift in aerial microbial communities suggested that dust deposition can also introduce new soil-derived microorganisms, which may include pathogens, and consequently might lead to diverse effects on the environment and public health ${ }^{18-20}$. In the present study we analysed the cultivable microbial communities during PSD and DSD in Mumbai, Lonavala and Pune.

The $\mathrm{PM}_{2.5} / \mathrm{PM}_{10}$ ratios during PSD were below the threshold $\left(0.5-0.6 \mu \mathrm{g} / \mathrm{m}^{3}\right)$ in all the three sites indicating 

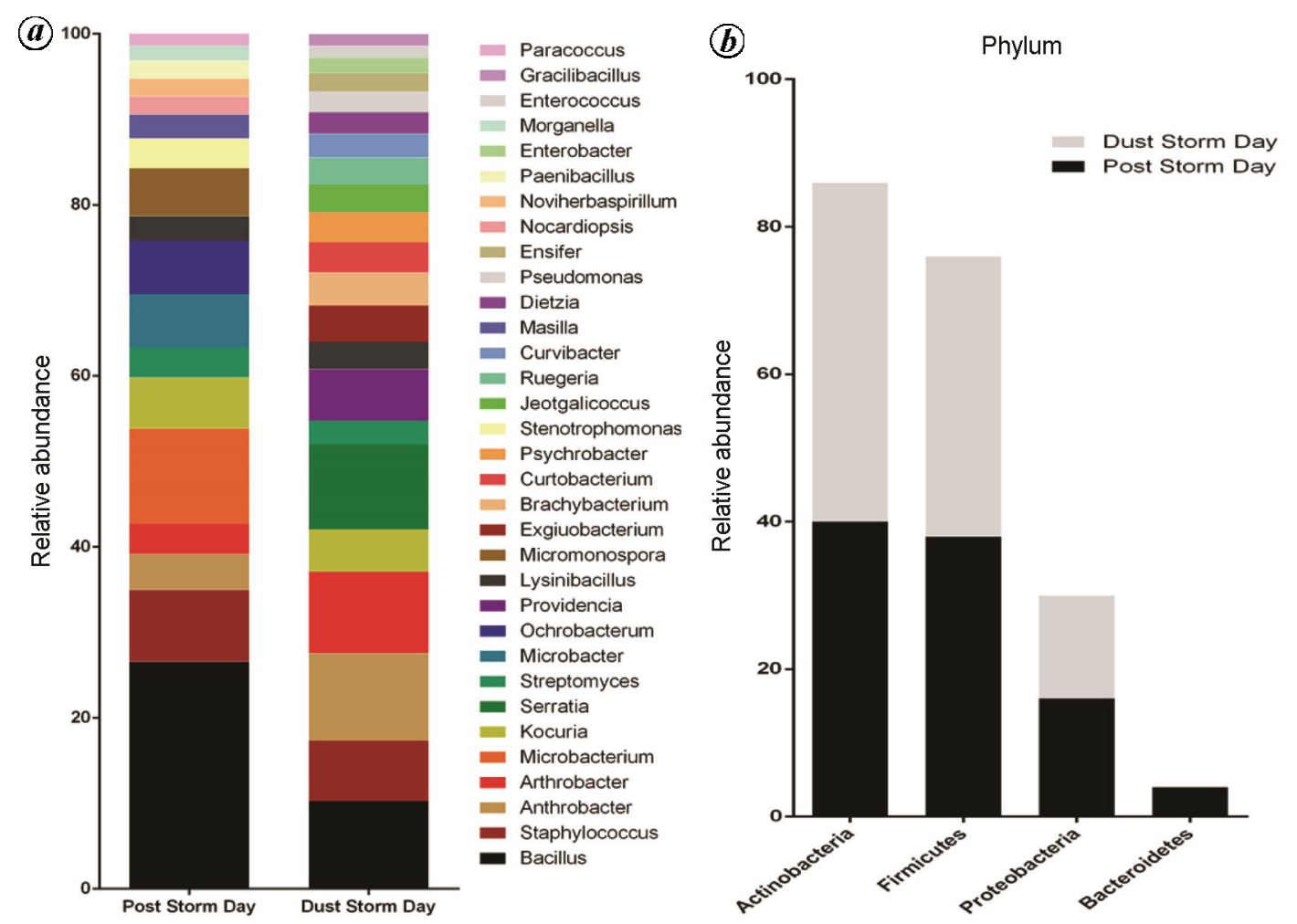

Figure 3. $\boldsymbol{a}$, Distribution and abundance of genera. $\boldsymbol{b}$, Relative abundance of four major phyla in PSD and DSD samples.
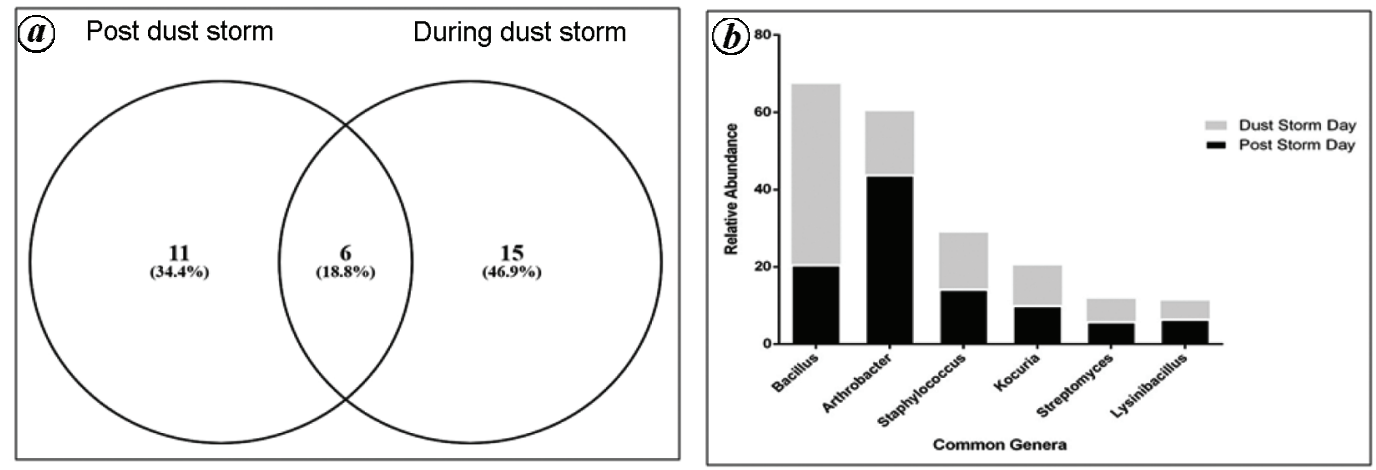

Figure 4. $\boldsymbol{a}$, Venn diagram showing shared genera between PSD and DSD samples. $\boldsymbol{b}$, Relative abundance of six genera shared by PSD and DSD samples.

a good air quality (Table 1). A comparison of data on GIS topography, land use and vegetation indicated that dust deposition and PM concentration in these sites are generally low ${ }^{21,22}$. A significant $(P<0.05)$ increase was observed in $\mathrm{PM}_{2.5} / \mathrm{PM}_{10}$ ratios during DSD, suggesting depletion of air quality in the sites due to dust storm (Table 1). A similar impact on air quality (particle matter concentration) has also been observed during dust storm events in Cairo, Egypt and Ahvaz, Iran ${ }^{9,22}$.

The different climatic conditions, sampling conditions, sampling time, particle concentrations, anthropogenic activities, types of region and population densities influence diversity of aerial microbial communities ${ }^{6}$. In the present study, microbial count recorded during DSD was significantly high compared to that recorded during PSD, thus revealing the impact of dust storms on aerial microbial build-up (Table 2). Our findings are consistent with other similar studies conducted across Iran, Egypt and the Mediterranean region ${ }^{21-24}$. The higher microbial count during DSD was recorded at all sampling sites (Table 2). However, a steady decrease in microbial count was observed for sampling sites. The highest count was recorded in Mumbai, followed by Lonavala and Pune. Among the growth media, R2A supported the growth of maximum microbial colonies, suggesting the presence of oligotrophic microorganisms in the air. Zhang considered R2A medium suitable for isolation of oligotrophic microorganisms from environmental habitats.

Identification of microorganisms by MALDI-TOF MS is rapid, cost-effective and becoming the technique of 


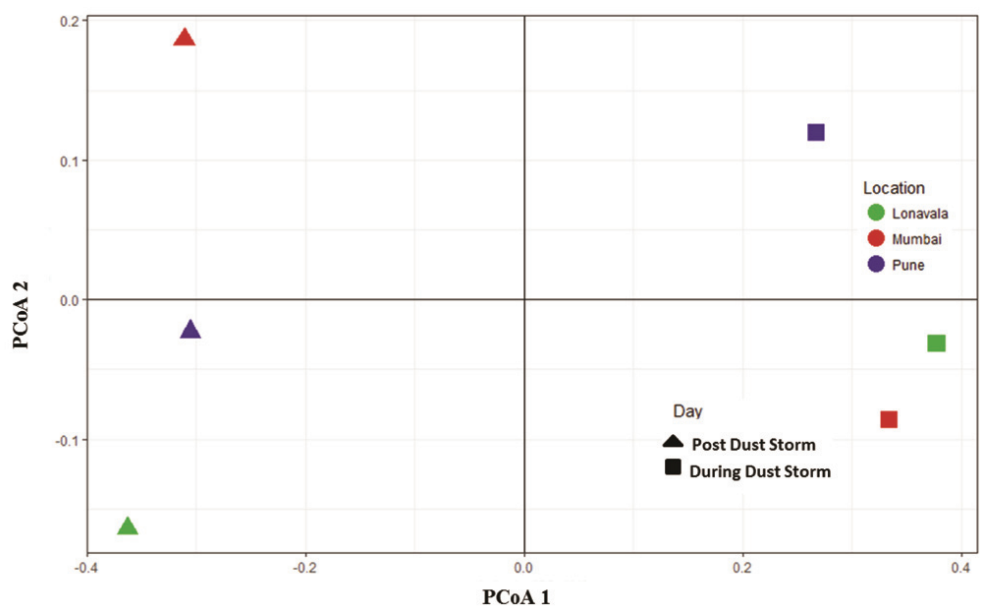

Figure 5. Principal coordinate analysis bi-plot constructed based on the microbial community composition of PSD and DSD samples.
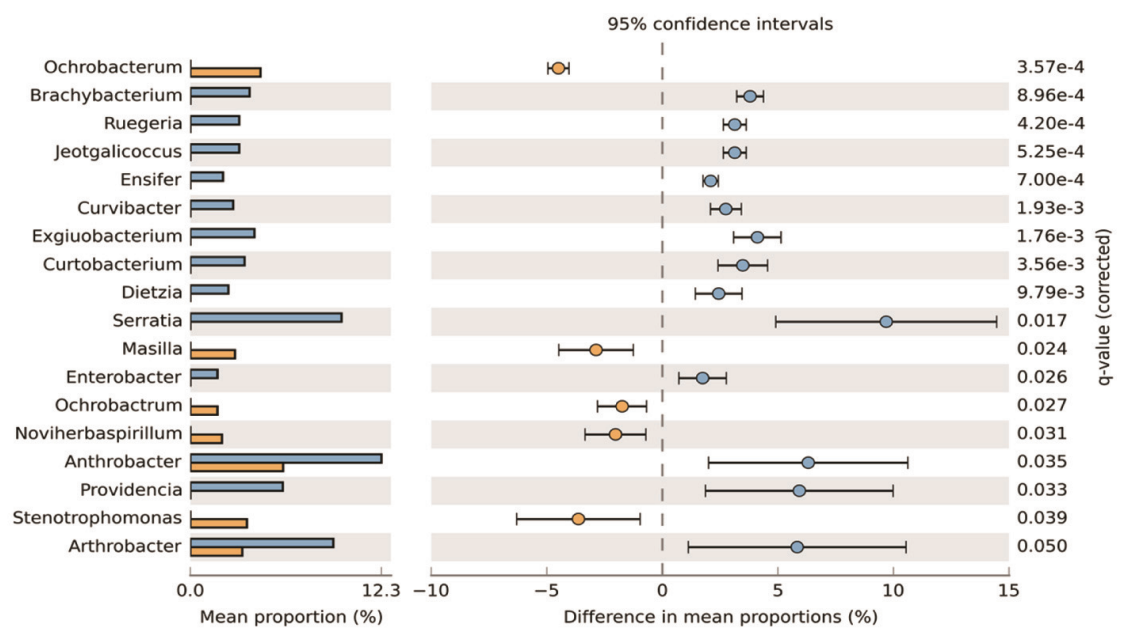

Figure 6. Extended bar plot representing the differential abundant genera present in PSD and DSD samples.

choice for high-throughput microbial identification ${ }^{10}$. MALDI-TOF MS allowed species-level identification of 310 isolates and dereplication of 580 isolates. The identified genera members are well represented in the Biotyper database. The isolates with 'no reliable identification' in MALDI-TOF-MS were further identified by sequencing of 16S rRNA gene, and belonged to the genera Micromonospora, Nocardiopsis, Curtobacterium, Exgiuobacterium, Noviherbaspirillum and Psychrobacter, which might be because of their underrepresentation in the Biotyper database ${ }^{10}$. Identification of the members of Bacillus, Staphylococcus, Arthrobacter, Microbacterium and Enterobacter by MALDI-TOF MS has remained inconsistent in various studies ${ }^{25-27}$. Identification of few selected isolates by both techniques provided in the same results confirm the accuracy of MALDI-TOF MS-based identifications.

The high Good's coverage for PSD (0.929) and DSD (0.966) indicated good sampling depth, suggesting that the isolates picked for identification are representing the total cultivated members, and the chances to get any new unique species are low (Table 3). However, the values for Good's coverage in this study are relatively lower to those observed by uncultivable methods for dust storms in Syria, Saudi Arabia and North Africa ${ }^{20}$. Similar values for all diversity indices were recorded during PSD and DSD, signifying minimal impact of the dust storm on species richness (Table 3).

A total of 32 bacterial genera and four fungus genera were identified, indicating high diversity of microorganisms in the air samples (Table 3). A similar study during an African dust storm showed the presence of 25 bacterial and 10 fungal genera ${ }^{24}$. Bacillus, Arthrobacter, Staphylococcus, Kocuria, Streptomyces and Lysinibacillus were common genera recorded during both sampling days, representing $50 \%$ of the total isolates (Figures 4 and 6). Bacteria belonging to these genera have been reported frequently from air and many other habitats ${ }^{4,5,20-22,28,29}$. Though there were few common genera, the overall microbial composition isolated from air differed significantly during DSD and PSD (Figure 6). Members of 15 genera were specifically present during DSD and 11 genera 
during PSD, indicating a shift in microbial communities in response to the dust storm. Among the specific genera, isolates belonging to Serratia were present in high proportions were present during DSD while isolates belonging to Microbacterium during PSD. The abundance of Psychrobacter adeliensis (3.53\%) and Exiguobacterium aurantiacum (4.24\%) during DSD, which are well-known osmotolerants and halotolerants, indicated their survival and possible migration along with dust storms ${ }^{30-35}$. Species-level comparison at all three sites showed a dynamic change in microbial composition during PSD and DSD (Supplementary Table $3 a, b$ and Supplementary Figure 1). The fungal isolates belonged to four genera, Aspergillus, Alternaria, Curvularia and Cladosporium, of which Cladosporium was uniquely present in DSD (Supplementary Table 3). Members of genus Aspergillus were recorded during both days, but Aspergillus niger was specifically recorded during PSD and Aspergillussy dowii during DSD. Various reports have shown the frequent occurrence of $A$. dowii in sea fan corals in the Caribbean Sea, Australian coast of the Indian Ocean and Pacific Ocean ${ }^{36-38}$. On the contrary, A. niger has been considered as normal flora in the air, especially in indoor environments ${ }^{39}$. The specieslevel identification of microbial isolates recovered during dust storm and post-dust storm sampling, lead us to the identification of marker microbial species, which are specifically present during a dust storm event.

The shift in microbial composition could be attributed to the fact that several microorganisms were transported from the origin of the dust storm and introduced into the aerial microbial communities of the sampling sites. The spread of microorganisms along with dust storms has been demonstrated previously in the case of an African desert storm reaching the Caribbean $\mathrm{Sea}^{24}$. Our study corroborates well with previous observations revealing that the major portion of aerial microbial communities comprised microbes of terrestrial origin ${ }^{21,40}$.

The separate grouping of samples from DSD and PSD in the PCoA bi-plot demonstrated the heterogeneity in microbial composition (Figure 5). The abundance of 13 genera was significantly higher in DSD samples and five genera in PSD samples which contributed to the specific grouping of these samples in PCoA plot (Figures 5 and 6). A similar shift in microbial abundance of Acinetobacter and Pseudomonas was seen in studies conducted by Griffin et al. ${ }^{28,41}$. Detailed literature survey on the possible pathogenicity of microorganisms recorded during this study revealed that members of Lysinibacillus (1.1\%) were opportunistic human pathogens, those of Ochrobacterum, Bacillus and Microbacterium (9.1\%) were human pathogens and few members of Bacillus (4.5\%) were plant pathogens in PSD samples (Supplementary Tables 4 and 5). An increase in the proportion of microorganisms was observed during DSD, viz. for members of Arthrobacter, Bacillus, Exiguobacterium and Providencia $(8.11 \%)$ which were opportunistic human pathogens, while few members of Arthrobacter, Bacillus, Dietzia, Enterococcus, Pseudomonas and Serratia (20.88\%) were human pathogens and some members of Arthrobacter and Curvibacter $(6.66 \%)$ were animal pathogens ${ }^{40,42,43}$. The presence of stress-tolerant, opportunistic and potential pathogens as marker microbial species in the samples collected during DSD, indicated the plausible spread of these organisms along with dust particles. This study has generated preliminary but essential information on the microbial population structure during and post dust storm events. However, we recognize that inclusion of more sampling points and analysis of microbial communities using next-generation sequencing approaches followed by high-throughput cultivation will generate more specific information.

In conclusion, this study provides a comprehensive comparison between bacterial communities in aerial dust that originated in the Middle East and travelled across Indian cities. Considering the expected changes in the severity, frequency and origin of dust storms, it suggests that dust storm-induced fluctuations in microbial community composition and presence of specific microbial species during a dust storm event will be helpful in generating information for microbial surveillance.

Conflict of interest: The authors declare no conflict of interest.

1. Mosttafiz, S. B., Rahman, M. and Rahman, M., Biotechnology: role of microbes in sustainable agriculture and environmental health. Internet J. Microbiol., 2012, 10, 5580.

2. Barberán, A., Henley, J., Fierer, N. and Casamayor, E. O., Structure, inter-annual recurrence, and global-scale connectivity of airborne microbial communities. Sci. Total Environ., 2014, 487, 187-195.

3. Sissakian, V. K., Al-Ansari, N. and Knutsson, S., Sand and dust storm events in Iraq. Nat. Sci., 2013, 5, 1084-1094.

4. Griffin, D. and Kellogg, C., Dust storms and their impact on Ocean and human health: dust in Earth's atmosphere. Ecohealth, 2004, 1, 284-295.

5. Kellogg, C. A., Griffin, D. W., Garrison, V. H., Peak, K. K., Royall, N. and Smith, R. R., Characterization of aerosolized bacteria and fungi from desert dust events in Mali, West Africa. Aerobiologia (Bologna), 2004, 20, 99-110.

6. Griffin, D. W., Atmospheric movement of microorganisms in clouds of desert dust and implications for human health. Clin. Microbiol. Rev., 2007, 20, 459-477.

7. Carlquist, S., The biota of long-distance dispersal. V. Plant dispersal to Pacific islands. Bull. Torrey Bot. Club, 1967, 94, 129-162.

8. Määttänen, A., Fouchet, T., Forni, O., Forget, F., Savijärvi, H. and Gondet, B., A study of the properties of a local dust storm with Mars Express OMEGA and PFS data. Icarus, 2009, 201, 504-416.

9. Talamantes, J., Behseta, S. and Zender, C. S., Statistical modeling of valley fever data in Kern County, California. Int. J. Biometeorol., 2007, 51, 307-313.

10. Rahi, P., Prakash, O. and Shouche, Y. S., Matrix-assisted laser desorption/ionization time-of-flight mass-spectrometry (MALDI-TOF MS) based microbial identifications: challenges and scopes for microbial ecologists. Front. Microbiol., 2016, 7, 1-12.

11. Barghouthi, S. A., A universal method for the identification of bacteria based on general PCR primers. Indian J. Microbiol., 2011, 51, 430-444. 


\section{RESEARCH ARTICLES}

12. Paithankar, K. R. and Prasad, K. S. N., Precipitation of DNA by polyethylene glycol and ethanol. Nucleic Acids Res., 1991, 19, 1346.

13. Kim, O. S., Cho, Y. J., Lee, K., Yoon, S. H., Kim, M. and Na, H., Introducing EzTaxon-e: a prokaryotic 16s rRNA gene sequence database with phylotypes that represent uncultured species. Int. J. Syst. Evol. Microbiol., 2012, 62, 716-721.

14. Hughes, J. B. and Bohannan, B. J. M., Application of ecological diversity statistics in microbial ecology. Molecular Microbial Ecology Manual, Springer, Berlin, Germany. Park, 2004, 2nd edn, pp. 1-24.

15. Swap, R., Garstang, M., Greco, S., Talbot, R. and Kållberg, P., Saharan dust in the Amazon Basin. Tellus B, 1992, 44, 133-149.

16. Kaufman, Y. J., Koren, I., Remer, L. A., Tanré, D., Ginoux, P. and Fan, S., Dust transport and deposition observed from the TerraModerate Resolution Imaging Spectroradiometer (MODIS) spacecraft over the Atlantic Ocean. J. Geophys. Res. D, 2005, 110, 1-16.

17. Gallisai, R., Peters, F., Volpe, G., Basart, S. and Baldasano, J. M., Saharan dust deposition may affect phytoplankton growth in the Mediterranean Sea at ecological time scales. PLoS ONE, 2014, 9(10), e110762.

18. Peter, H., Hörtnagl, P., Reche, I. and Sommaruga, R., Bacterial diversity and composition during rain events with and without Saharan dust influence reaching a high mountain lake in the Alps. Environ. Microbiol. Rep., 2014, 6, 618-624.

19. Bowers, R. M., Sullivan, A. P., Costello, E. K., Collett, J. L., Knight, R. and Fierer, N., Sources of bacteria in outdoor air across cities in the midwestern United States. Appl. Environ. Microbiol. 2011, 77, 6350-6356.

20. Gat, D., Mazar, Y., Cytryn, E. and Rudich, Y., Origin-dependent variations in the atmospheric microbiome community in eastern Mediterranean dust storms. Environ. Sci. Technol., 2017, 51, 6709-6718.

21. Goudarzi, G., Shirmardi, M., Khodarahmi, F., Hashemi-Shahraki, A., Alavi, N. and Ankali, K. A., Particulate matter and bacteria characteristics of the Middle East Dust (MED) storms over Ahvaz, Iran. Aerobiologia (Bologna), 2014, 30, 345-356.

22. Zakey, A. S., Abdel-Wahab, M. M., Pettersson, J. B. C., Gatari, M. J. and Hallquist, M., Seasonal and spatial variation of atmospheric particulate matter in a developing megacity, the Greater Cairo, Egypt. Atmosfera, 2008, 21, 171-189.

23. Shaffer, B. T. and Lighthart, B., Survey of airborne bacteria at four diverse locations in Oredgon urban, rural, forest, and coastal. Microb. Ecol., 1997, 34, 167-177.

24. Polymenakou, P. N., Mandalakis, M., Stephanou, E. G. and Tselepides, A., Particle size distribution of airborne microorganisms and pathogens during an intense African dust event in the eastern Mediterranean. Environ. Health Perspect., 2008, 116, 292-296.

25. Starostin, K. V., Demidov, E. A., Bryanskaya, A. V., Efimov, V. M., Rozanov, A. S. and Peltek, S. E., Identification of Bacillus strains by MALDI TOF MS using geometric approach. Sci. Rep., $2015,5,1-9$.

26. Wang, W., Xi, H., Huang, M., Wang, J., Fan, M. and Chen, Y., Performance of mass spectrometric identification of bacteria and yeasts routinely isolated in a clinical microbiology laboratory using MALDI-TOF MS. J. Thorac. Dis., 2014, 6, 524-533.

27. Manukumar, H. M. and Umesha, S., MALDI-TOF-MS based identification and molecular characterization of food associated methicillin-resistant Staphylococcus aureus. Sci. Rep., 2017, 7, 116.

28. Griffin, D. W., Westphal, D. L. and Gray, M. A., Airborne microorganisms in the African desert dust corridor over the midAtlantic ridge, Ocean Drilling Program, Leg 209. Aerobiologia (Bologna), 2006, 22, 211-226.

29. Mazar, Y., Cytryn, E., Erel, Y. and Rudich, Y., Effect of dust storms on the atmospheric microbiome in the Eastern Mediterranean. Environ. Sci. Technol., 2016, 50, 4194-4202.
30. Vishnivetskaya, T. A., Kathariou, S. and Tiedje, J. M., The Exiguobacterium genus: biodiversity and biogeography. Extremophiles, 2009, 13, 541-455.

31. Rodrigues, D. F., Da, C., Jesus, E., Ayala-Del-Río, H. L., Pellizari, V. H., Gilichinsky, D. and Sepulveda-Torres, L., Biogeography of two cold-adapted genera: Psychrobacter and Exiguobacterium. ISME J., 2009, 3, 658-665.

32. Strahsburger, E., Zapata, F., Pedroso, I., Fuentes, D., Tapia, P. and Ponce, R., Draft genome sequence of Exiguobacterium aurantiacum strain PN47 isolate from saline ponds, known as - Salar del Huascoll located in the Altiplano in the North of Chile. Braz. J. Microbiol., 2018, 49, 7-9.

33. Collins, M. D., Lund, B. M., Farrow, J. A. E. and Schleifer, K. H., Chemotaxonomic study of an alkalophilic bacterium, Exiguobacterium aurantiacum gen. nov., sp. nov. Microbiology, 1983, 129, 2037-2042.

34. Bozal, N., Montes, M. J., Tudela, E. and Guinea, J., Characterization of several Psychrobacter strains isolated from Antarctic environments and description of Psychrobacter luti sp. nov. and Psychrobacter fozii sp. nov. Int. J. Syst. Evol. Microbiol., 2003, 53, 1093-1100.

35. Dias, L. M., Folador, A. R. C., Oliveira, A. M., Ramos, R. T. J., Silva, A. and Baraúna, R. A., Genomic architecture of the two cold-adapted genera Exiguobacterium and Psychrobacter: evidence of functional reduction in the Exiguobacterium antarcticum B7 genome. Genome Biol. Evol., 2018, 10, 731-741.

36. Hallegraeff, G., Coman, F., Davies, C., Hayashi, A., McLeod, D. and Slotwinski, A., Australian dust storm associated with extensive Aspergillus sydowii fungal-Blooml in coastal waters. Appl. Environ. Microbiol., 2014, 80, 3315-3320.

37. Soler-Hurtado, M. M., Sandoval-Sierra, J. V., Machordom, A. and Diéguez-Uribeondo, J., Aspergillus sydowii and other potential fungal pathogens in Gorgonian octocorals of the Ecuadorian Pacific. PLoS ONE, 2016, 11, 1-12.

38. Rivest, E. B., Baker, D. M., Rypien, K. L. and Harvell, C. D., Nitrogen source preference of Aspergillus sydowii, an infective agent associated with aspergillosis of sea fan corals. Limnol. Oceanogr., 2010, 55, 386-392.

39. Gautam, A. K., Sharma, S., Avasthi, S. and Bhadauria, R., Diversity, pathogenicity and toxicology of $A$. niger: an important spoilage fungi. Res. J. Microbiol., 2011, 6, 270-280.

40. Chen, S. J., Hsieh, L. T., Kao, M. J., Lin, W. Y., Huang, K. L. and Lin, C. C., Characteristics of particles sampled in southern Taiwan during the Asian dust storm periods in 2000 and 2001. Atmos. Environ., 2004, 38, 5925-5934.

41. Griffin, D. W., Kellogg, C. A., Garrison, V. H., Lisle, J. T., Borden, T. C. and Shinn, E. A., Atmospheric microbiology in the northern Caribbean during African dust events. Aerobiologia (Bologna), 2003, 19, 143-157.

42. Nourmoradi, H., Moradnejadi, K., Moghadam, F. M., Khosravi, B., Hemati, L. and Khoshniyat, R., The effect of dust storm on the microbial quality of ambient air in Sanandaj: a city located in the West of Iran. Global J. Health Sci., 2015, 7, 46888.

43. An, S., Sin, H. H. and DuBow, M. S., Modification of atmospheric sand-associated bacterial communities during Asian sandstorms in China and South Korea. Heredity (Edinb.), 2015, 114, 460-467.

ACKNOWLEDGEMENTS. We thank the Department of Biotechnology, Government of India for financial support (grant no. BT/Coord. II/01/03/2016) and the Centre for Citizen Science, Pune for help during sampling and obtaining the meteorological data. We also thank Achyut Kumar and Tanisha Dhakephalkar for help during the experiments and Prof. Durga Pawar, Department of Microbiology, Khalsa College, Mumbai for collecting the samples at Mumbai.

Received 25 February 2019; revised accepted 25 July 2019

doi: $10.18520 / \mathrm{cs} / \mathrm{v} 117 / \mathrm{i} 10 / 1693-1700$ 